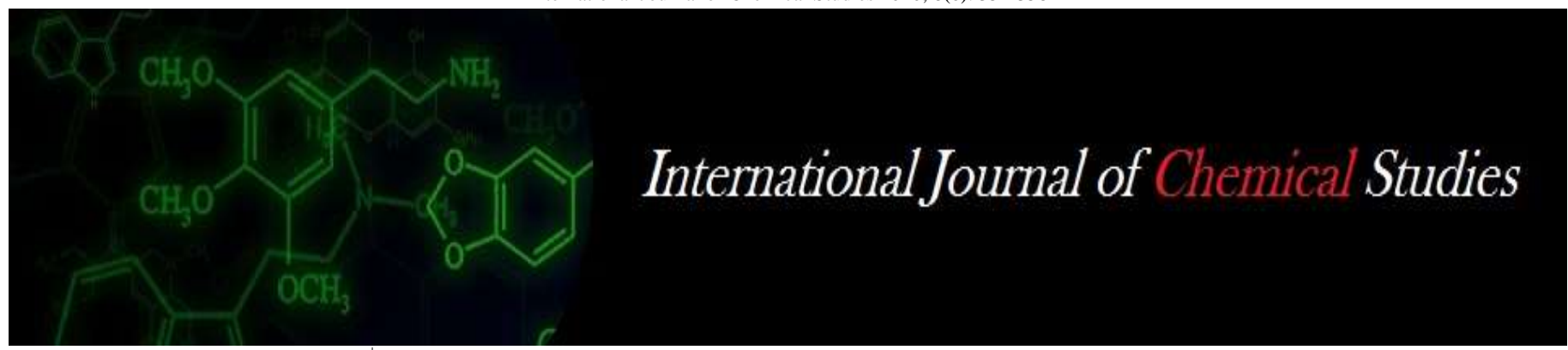

P-ISSN: 2349-8528

E-ISSN: 2321-4902

www.chemijournal.com

IJCS 2020; 8(6): 354-358

(C) 2020 IJCS

Received: 09-09-2020

Accepted: 15-10-2020

Swagat Shubhadarshi

Department of Agronomy,

School of Agriculture,

Lovely Professional University, Jalandhar, Punjab, India

Dr. Sarvjeet Kukreja

Department of Agronomy,

School of Agriculture,

Lovely Professional University,

Jalandhar, Punjab, India

\section{Hydrogel: Promising alternative for water and nutrient management}

\author{
Swagat Shubhadarshi and Dr. Sarvjeet Kukreja
}

DOI: https://doi.org/10.22271/chemi.2020.v8.i6e.10794

\begin{abstract}
Nowadays water management is considered as one of the major challenges for all countries. It is estimated that by 2030 , global water demand is probable to be $50 \%$ higher than today and this will lead us towards water scarcity, at the same time agricultural sector used over 70 percent of freshwater in most regions of the world. Among all the cultivated areas in India $60 \%$ lands are under dryland condition and $30 \%$ area has less rainfall. So, cultivation under shortage of water is a major problem in India. Under such condition, application of hydrogel can be used as an alternative which can reduce the problem of water scarcity. Hydrogels are the network of crosslinked polymer chains which can swell to absorb huge volume of water. Hydrogel releases water and nutrient to the plants when soils around root zone of plants starts to dry up. Application of hydrogel polymer creates a water reservoir near the root zone of plants, improve the capacity of available water to plant, enhances plant growth and increases yield and hence reduces cost of cultivation. Hence, hydrogel plays an important role in modern agriculture.
\end{abstract}

Keywords: hydrogel, water scarcity, dry land, nutrient management etc

\section{Introduction}

In 1950, per capita water availability in India was more than required that is 5000 cubic meter per annum. This amount has gone down in past few years. Now in India per capita water availability is 1700 cubic meter which is less than average. Now many parts of India are facing water crisis. Indian meteorological Department has announced October 2018 as the driest month after 1976. This gives an idea about the alarming changes in the environment (Bhaskar et al. 2013) ${ }^{[2]}$.

There are various reasons of water scarcity, among all dependency on monsoon is the most important. India mostly depends on monsoon to refill its water sources like lakes, rivers and reservoirs. Due to various environmental issues pattern and distribution of rainfall varies. Hence, it is necessary to manage the available water.

Now management of water is a major challenge for all the countries. It is estimated that by 2030 , total water requirement in the globe will be $50 \%$ higher than today and this will lead us towards water scarcity. At the same time agricultural sector used nearly 70 percent of freshwater almost in every developed and developing countries of the world. Among 195 countries in the world, India ranks 41 in the moisture stress (Sri Laxmi et al 2019) ${ }^{[8]}$. Agriculture is the field which is greatly affected by water scarcity.

India has nearly $2.4 \%$ of land and $4 \%$ of fresh water resources of the world, but India has $16 \%$ of the world's total population. For such a huge population the demand for food production is much higher, which needs more water. In 1999, water requirement of India was 593 billion cubic metres. It will increase to 1069 billion cubic meters by 2050 .

Water utilization in industrial, power and domestic sectors are very much less as compared to agricultural sector. So, it is difficult to reduce the use of water in this field. The research should focus to reduce utilization of water in agricultural sector as it uses a large amount of water. This problem can be minimized by the use of hydrogels. 

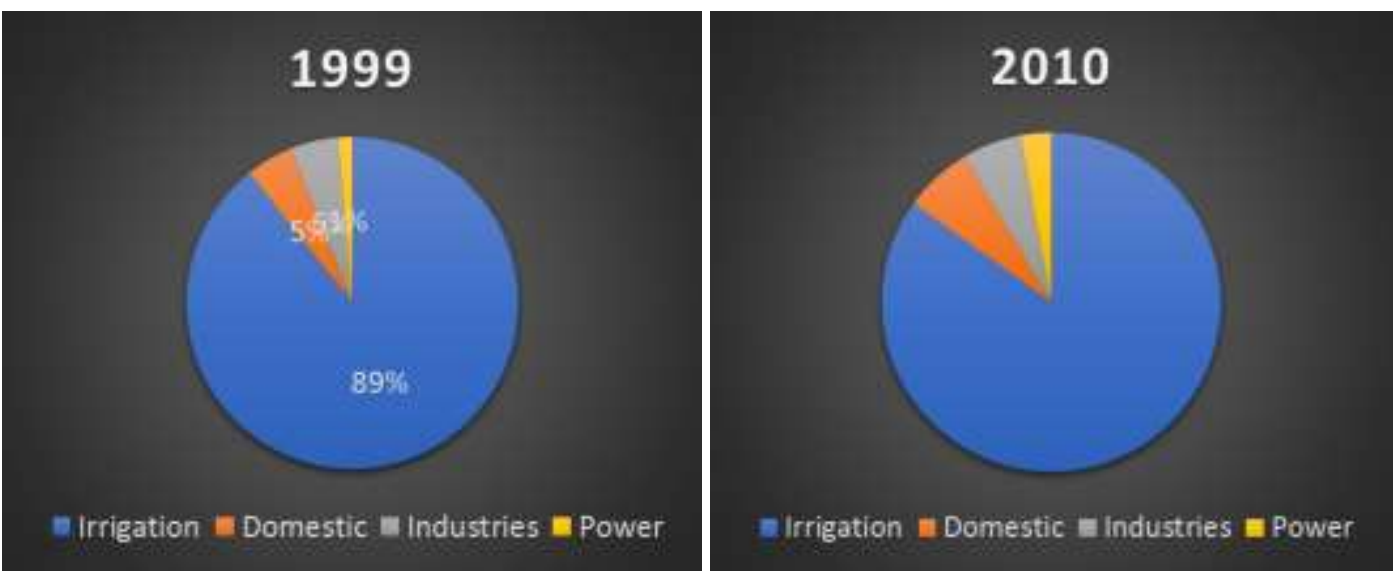

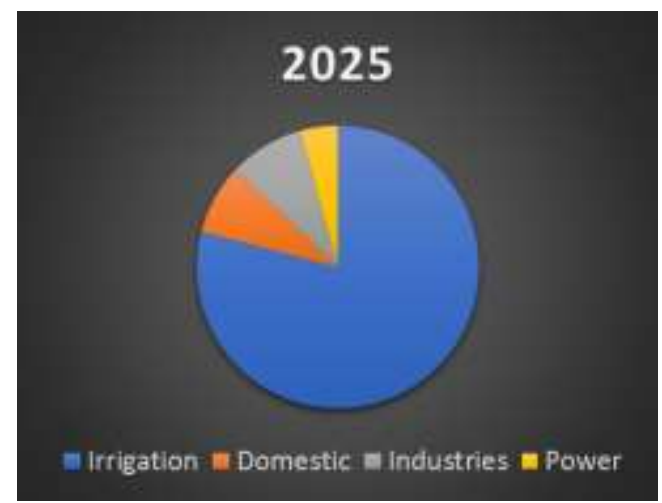

What is hydrogel

According to Lee and Kwon, the word hydrogel was first used in the year 1894. However, firstly it was not made for agricultural use. In 1960s it was first used in agriculture sector by USDA.

Hydrogels are crossed linked polymers, that can hold a huge amount of water. According to Bowman and Evans (1991), $1 \mathrm{gm}$ of super absorbent polymer can hold 400 to $1500 \mathrm{gms}$ of water. In his experiment, Johnson and Veltkamo (1985) found that proper management of hydrogel can permit $95 \%$ of stored water for plant absorption when root zone of a plant and its surroundings begin to dry.

The hydrophilic groups of the polymer chain cause absorption of water in hydrogels. The hydrophilic groups are acrylic acid, carboxylic acid, acrylamide, acrylate etc. Polyacrylamide $(\mathrm{C} 3 \mathrm{H} 5 \mathrm{NO})_{n}$ is most commonly used as a synthetic hydrogel and is a polymer formed from acrylamide hydrophilic group (Kalhapure et al. 2016). Polyacrylamide can be combined in two different ways one is simple linear chain structure another is cross-linked. Linear linked polyacrylamide dissolves in water so that it cannot be used as a hydrogel. And cross-linked polymers can be used as hydrogel using $\mathrm{N}, \mathrm{N}^{\prime}$-methylenebisacrylamide. It can also be used as a slow release fertilizer; however, this feature can reduce the hydration capacity of the polymer gel (Teodorescu et al., 2009).

\section{Characteristics feature of hydrogel}

- Absorbs 400 to 1500 times of water of its dry weight

- It works for a minimum time period of one year

- Hydrogels doesn't affect more by soil salinity

- Helps to minimize the leaching loss of herbicides and fertilizers

- Maintain the quality of soils

- Enhances rate of seed germination and seedling emergence rate

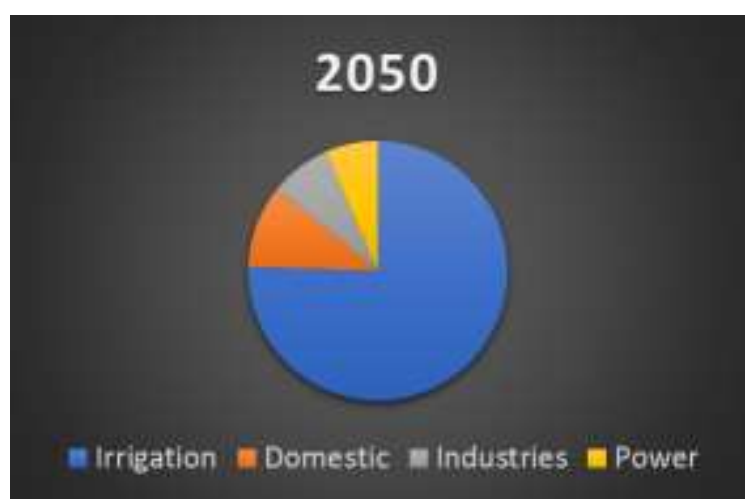

- Reduces irrigation requirement

- Helps in better root growth and density

- Application rate is 1-2 $\mathrm{kg}$ per ha for nursery horticultural crops and 2.5-5 kg per ha for field crops

- Application of hydrogel Helps plants to withstand prolonged moisture stress

- Delays arrival of the permanent wilting point

\section{Classification of hydrogel}

1. On the basis of source

- Natural hydrogels

- Synthetic hydrogels

- Hybrid

2. On the basis of preparation

- Homopolymer hydrogels

- Copolymeric hydrogels

- Interpenetrating polymeric hydrogel

3. On the basis of configuration

- Non-crystalline

- Semi crystalline

4. On the basis of charge on cross-linked chain

- Neutral

- Anionic

- Cationic

- Ampholytic

- Polybetaines

5. On the basis of type of cross linking

- Chemical cross-link

- Physical cross-link

6. On the basis of physical property

- Smart hydrogel

- Conventional hydrogel

7. On the basis of response

- Chemical response

- Biochemical response 


\section{Hydrogel usage in agriculture}

Use of hydrogel polymer is now capturing the interest of scientists in the field of agriculture. In agriculture, these gels can be used as a water reservoir which helps crops and soil to use water more efficiently. These are designed in such a way so as to solve the problems that they such as erosion, irrigation and water run-off. In some cases, it can increase soil aeration, permeability, soil texture and structure, infiltration of water (Abobatta et al. 2018) ${ }^{[1]}$. It also increases the microbial activity of the soil.

When soil become dry, hydrogels release water to the root zones. Presently scientists are developing new technologies, by which hydrogels produce nutrients to plants slowly. Slow releases fertilizers help to minimize the loss of nutrients by rain water or by irrigation water. Hence, hydrogels can improve the nutrient use efficiency by minimizing nutrient loss.

So, use of hydrogel polymer creates a waterbody near the root area of vegetation, lower osmotic moistureof soil, enhance plant capacity to be had water and boom entire yield and minimize cost of cultivation.

\section{Preparation of hydrogel}

Hydrogel is a cross linked matrix which produce elastic structure. Hence, hydrogels can be produced by those techniques which can create a cross-linked polymer. Both synthetic and natural polymers are cross-linked to form hydrogels in many ways, such as

- $\quad$ Linking of the polymer chains through chemical reaction

- By using ionizing radiation

- Physical interactions (entanglements, electrostatics, crystallite formation)

Hydrogels can be prepared by both synthetic and natural polymers. Synthetic polymer is hydrophobic and chemically stronger than natural polymers. The basic parts of hydrogel preparation are monomer, initiator and cross-linker.

Acrylamide, acrylic acid and its salts are the basic components of hydrogel preparation. In some cases, hydrogels can also be made from polar monomers.

\section{Application method of hydrogel}

One kg of hydrogel can absorb water up to 500-600 times of their weight base on salt content of water. Hydrogel are often applied wet (liquid) formulation or dry (granules) formulation.

\section{Dry application}

For proper functioning of hydrogel, it should be kept in a very dry place, so that it cannot absorb water. Mix the required amount of hydrogel $(5 \mathrm{~kg} / \mathrm{ha})$ with dry, fine sand of less than $0.25 \mathrm{~mm}$ size in an exceedingly 1:10 ratio. For better result in field crop, the hydrogel should be placed near the seeds. For nursery bed transplants $2 \mathrm{~g}$ per $\mathrm{m}^{2}$ of hydrogel should be applied uniformly 2 inches above the nursery field. Hydrogel should be applied in row line.

\section{Wet application}

Mix the hydrogel granules in water and permit them to rest for 60-90 min. Once the polymer is soaked properly, apply it in the field and the rate of application must be one part of soaked polymer to four parts of soil. While transplanting, liquid hydrogel should be applied. Before transplanting dip the roots in the solution, then it should be transplanted in the field. Some hydrophilic polymer used in agriculture are Pusa hydrogel, Agrosoak, Soil moist etc.

\section{Application rate of hydrogel}

\begin{tabular}{|c|c|}
\hline Type of Soil & Suggested dosage of Hydrogel \\
\hline Arid and Semi-arid Regions & $4-6 \mathrm{~g} / \mathrm{kg}$ soil \\
\hline $\begin{array}{c}\text { For all level of water stress } \\
\text { treatment and improved irrigation } \\
\text { time }\end{array}$ & $2.25-3 \mathrm{~g} / \mathrm{kg}$ soil \\
\hline $\begin{array}{c}\text { To slow down permanent wilting } \\
\text { point in sandy soils }\end{array}$ & $\begin{array}{c}0.2-0.4 \mathrm{~g} / \mathrm{kg} \mathrm{OR} 0.8 \% \text { of soil } \\
\text { whichever is more }\end{array}$ \\
\hline $\begin{array}{c}\text { To lower the irrigation water } \\
\text { requirement by 50\% in loamy soil }\end{array}$ & $2-4 \mathrm{~g} / \mathrm{plant}$ pit \\
\hline $\begin{array}{c}\text { To enhance relative water content } \\
\text { and leaf water use efficiency }\end{array}$ & $0.5-2.0 \mathrm{~g} / \mathrm{pot}$ \\
\hline To minimize drought stress & $0.2-0.4 \%$ of soil \\
\hline To prohibit drought stress totally & $225-300 \mathrm{~kg} / \mathrm{ha}$ of cultivated area \\
\hline To minimize water stress & $3 \%$ by weight \\
\hline
\end{tabular}

(Source: http://vikaspedia.in/agriculture/best-practices/sustainableagriculture/crop-management/hydrogelagriculture-technology)

\section{Effect of hydrogel on nutrients}

In agricultural sector hydrogel polymers can be used as a soil conditioner to maximize crop tolerance and growth in light weight or sandy gravels substrate. Hydrogel polymer has been used as a soil conditioner to reduce soil water loss and increase crop yield.

Application of hydrogel minimizes the loss of micronutrient by washing out to water tables and enhances the water consumption capacity. It reduces the amount of fertilization after the nutrient leaching is restricted by reducing runoff alternatively, dose of fertilizer adjustable in time because of hydrogel which contain fertilizer have control water released. The nutrient is obtainable for plants over an extended period instead of a rapid availability that ammonium nitrate, potassium chloride and ammonium phosphate.

\section{Effect of hydrogel on WHC}

Hydrogels contain carboxylic groups which helps them to create cationic bond and absorb water. Synthetic hydrogels are less damaged by fertilizer salts than natural hydrogels. Many factors affect water absorption of hydrogels. The availability of water in the soil is most important factor to various crops.

Arid and semiarid regions have limited irrigation facility. So, in this region application of hydrogel is useful (Bakass et al. 2002). Application of $2.5 \mathrm{~kg} / \mathrm{ha}$ hydrogel increased the water holding capacity of sandy soil from $171 \%$ to $402 \%$. Hydrogel lowers the irrigation requirements by improving water holding capacity in some crops. 

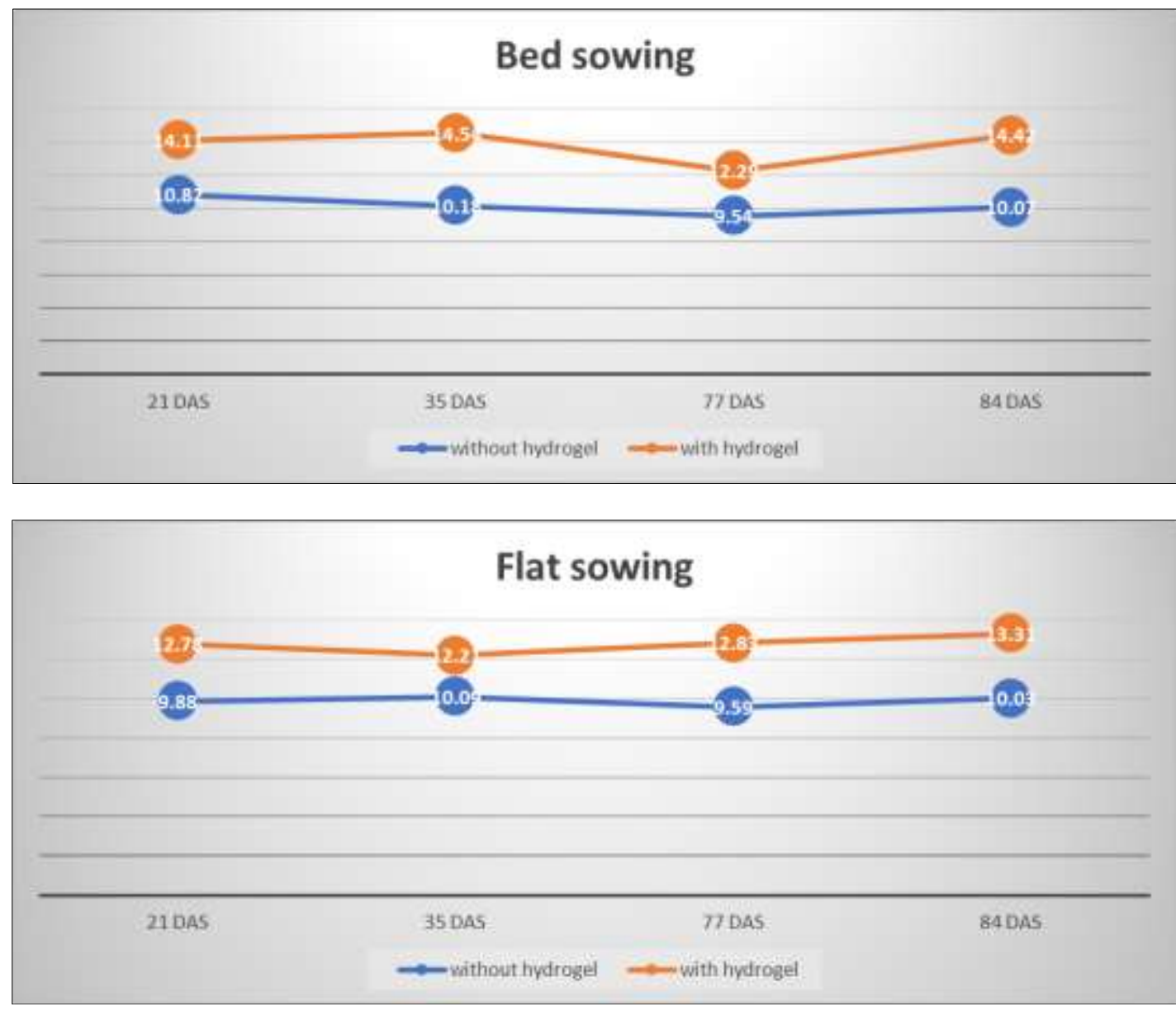

Fig 1: The table shows the data of moisture content of aerobic rice in 10-15 cm depth of soil (Rehman et al. 2011)

\section{Effect of evapotranspiration loss due to hydrogel}

\begin{tabular}{|c|c|}
\hline Type of soil & $\begin{array}{c}\text { Reduced evapotranspiration } \\
\text { loss (in kg/pot/day) }\end{array}$ \\
\hline Sandy loam & 0.015 \\
\hline Loam & 0.0067 \\
\hline Silt loam & 0.003 \\
\hline clay & 0.0065 \\
\hline
\end{tabular}

This table shows the difference between evapotranspiration loss of different hydrogel applied soils and controlled soil. Hydrogel was applied at a rate of $0.4 \%$ per pot (Agaba et al. 2010).

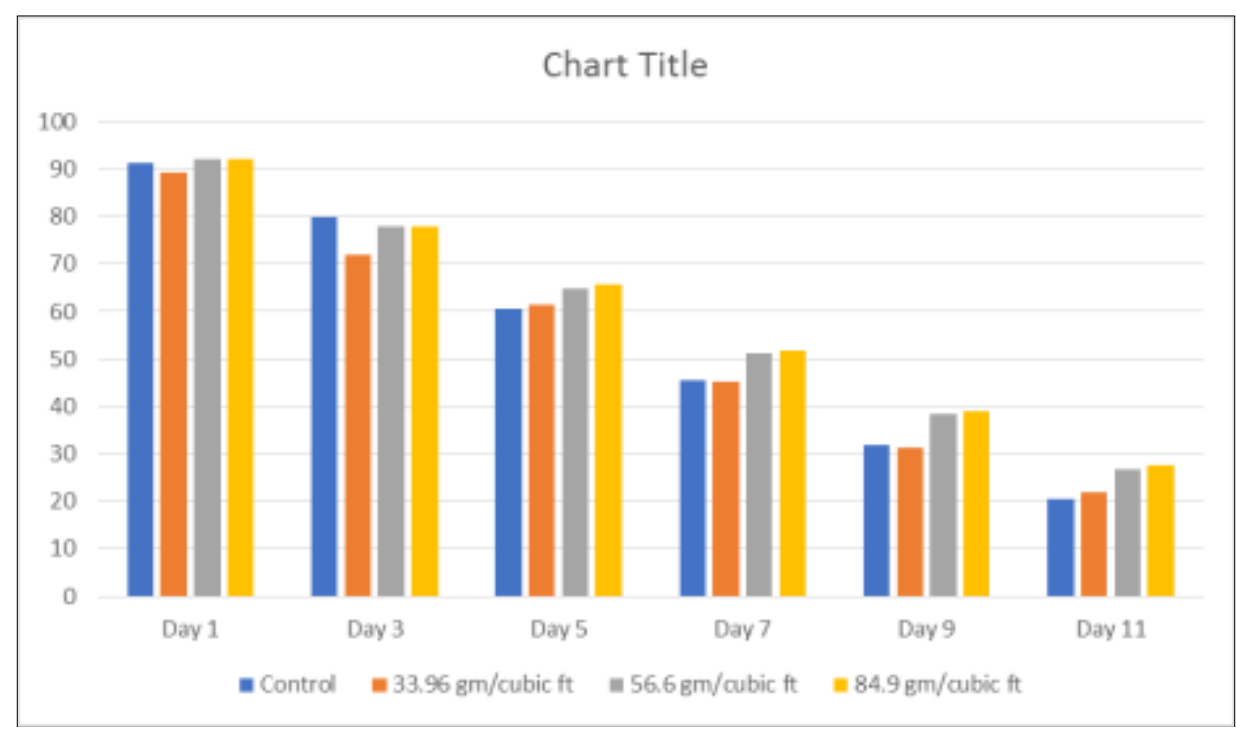

Fig 2: Percentage of water content over time in various concentration of hydrogel 


\section{Conclusion}

Application of hydrogel increases the productivity of crops like vegetables, flowers, cereals, etc. in arid and semi-arid regions. It also improves the soil properties, increases the soil water retention capacity, enhances the water holding capacity, improves irrigation capacity. In some cases, it improves the quality of agricultural outputs (size, colour and plant biomass). According to physical and chemical properties hydrogels can be used as a super absorbent in environment preservation in the agricultural sector.

\section{Reference}

1. Abobatta, W. Impact of hydrogel polymer in agricultural sector, Advances in Agriculture and Environmental Science, 2018;22(2):59-64.

2. Bhaskar N, Aggarwal $\mathrm{P}$, Kumar S, Meena MD. Significance of hydrogel and its application in agriculture. Indian Farming, 2013;62(10):15-17.

3. Buwalda SJ, Boere KW, Dijkstra PJ, Feijen J, Vermonden T, Hennink WE. Hydrogels in a historical perspective: From simple networks to smart materials, Journal of controlled release, 2014;190:254-273.

4. Choudhary SK, Jat AL, Upadhyay PK, Singh RK. Hydrogel: The Potentialities to Produce More Crops per Drop in Agriculture, Popular Kheti 2014;2:1167-1172.

5. Dehkordi KD. Effect of superabsorbent polymer on salt and drought resistance of eucalyptus globulus. Applied Ecology and Environmental Research, 2017;15(4):17911802.

6. Kalhapure A, Kumar R, Singh VP, Pandey DS. Hydrogels: a boon for increasing agricultural productivity in water-stressed environment, Current Science, 2016;111(11):1773-1779.

7. Kreye C, Bouman BAM, Castaneda AR, Lampayan RM, Faronilo JE, Lactaoen AT, et al. Possible causes of yield failure in tropical aerobic rice. Field Crops Research, 2009;111:197-206.

8. Laxmi S, Chanu PK, Rani P, Rai S, Prasad SK, Singh RK. Effect of hydrogel on soil moisture stress, Journal of Pharmacognosy and Phytochemistry, 2019;SP5:316-320.

9. Meng Yi, Lu Jie, Cheng Yi, Li Qiang, Wang Haisong. Lignin-based hydrogels: A review of preparation, properties, and application, International Journal of Biological Macromolecules2019;135:1006-1019.

10. Montesano FF, Parente A, Santamaria P. Biodegradable superabsorbent hydrogel increases water retention properties of growing media and plant growth. Agriculture and Agricultural Science Procedia, 2015;4:451-458.

11. Neethu TM, Dubey PK, Kaswala AR. Prospects and Applications of Hydrogel Technology in Agriculture, International Journal of Current Microbiology and Applied Sciences. 2018;7(5):3155-3162.

12. Ovalesha MA, Yadav B, Rai PK. Effects of polymer seed coating and seed treatment on plant growth, seed yield and quality of Cowpea (Vigna unguiculata). Journal of Pharmacognosy and Phytochemistry, 2017;6(4):106-109.

13. Ropek D, Kulikashi E. Potential of Hydrogel application on plant growth, Ecological chemistry and Engineering, 2009;9(16):1191-1199

14. Shankarappa S. Standardizing the Hydrogel Application Rates and Foliar Nutrition for Enhancing Yield of Lentil (Lens culinaris), MDPI journal, 2020;420(8):2-10.

15. Xiang Y, Zhang G, Chen C, Liu B, Cai D, Wu Z. Fabrication a pH-responsively controlled-release pesticide using an attapulgite-based hydrogel. ACS Sustainable Chem. Eng., 2018;6(1):1192-1201. 